\title{
O PROCESSO DE FEMINIZAÇÃO DO MAGISTÉRIO NO BRASIL DO SÉCULO 19: COEDUCAÇÃO OU ESCOLAS MISTAS ${ }^{1}$
}

DOI: http://dx.doi.org/10.1590/2236-3459/51341

\author{
André Paulo Castanha \\ Universidade Estadual do Oeste do Paraná, Brasil.
}

\section{Resumo}

O estudo tem como propósito compreender o processo de feminização do magistério, tendo como foco central sua relação com a coeducação. Para tanto, analiso alguns discursos de intelectuais, professores e autoridades que defendiam a prática da coeducação nas escolas públicas primárias e procuro demonstrar como tais discursos fizeram eco na sociedade, levando a sua materialização na legislação educacional a partir de meados do século 19. O texto traz uma comparação entre as ações implantadas na Corte e nas províncias do Rio de Janeiro, Mato Grosso e Paraná, articulando discursos e a legislação. A interpretação das fontes utilizadas permite afirmar que os debates e encaminhamentos em torno da coeducação foram elementos centrais para o processo de feminização do magistério. Em torno deles um número cada vez maior de indivíduos, sejam eles autoridades, professores e intelectuais defenderam o trabalho das mulheres no magistério primário, levando à construção de bases legais que garantiam/estimulavam o trabalho feminino nas escolas.

Palavras-chave: educação no Brasil, século 19, coeducação, feminização do magistério, legislação educacional.

\section{THE PROCESS OF FEMINIZATION OF TEACHING IN BRAZIL AT THE NINETEENTH CENTURY: COEDUCATION AND MIXED SCHOOLS}

Abstract

This study aims to understand the process of feminization of teaching with the central focus on its relationship with the coeducation. Therefore, I analyse some intellectuals, teachers and authorities' speeches that defended the coeducation's practice in public primary schools and I search to show how such speeches did echo in society, leading to its materialization in educational legislation by the middle of the nineteenth century. The text brings a comparison between the actions implemented in

\footnotetext{
${ }^{1}$ Uma versão similar reduzida deste texto foi apresentada como comunicação oral e publicada nos Anais de $36^{a}$ Reunião Científica Anual da Associação Nacional de Pesquisa e Pós-Graduação em Educação, realizada em Goiânia, em 2013. 
the Court and in the Rio de Janeiro, Mato Grosso and Paraná Provinces, enunciating speeches and the legislation. The interpretation of the sources used to suggest that the debates and routing around the coeducation were central element to the process of teaching's feminization. Around them, an increasing number of individuals, like authorities, teachers and intellectuals, put themselves in defense of women's work in primary teaching, leading to create the legal bases that ensured/encouraged female participation in schools.

Key-words: education in Brazil, nineteenth century, coeducation, feminization of teaching, educational legislation

\section{LO PROCESO DE ENSEÑANZA EN BRASIL FEMINIZACION SIGLO 19: COEDUCACION O LA EDUCACIÓN MIXTA}

\section{Resumen}

El estudio tiene como objetivo comprender el proceso de feminización de la profesión docente, con el foco central de su relación con la coeducación. Para ello, se analizan los discursos de intelectuales, académicos y funcionarios que defendieron la práctica de la coeducación en las escuelas primarias públicas y tratan de mostrar cómo estos discursos se hicieron eco en la sociedad, que conducen a su materialización en la legislación educativa de mediados del siglo 19. El texto se presenta una comparación entre las acciones emprendidas en la Corte y en las provincias de Río de Janeiro, Mato Grosso y Paraná, los discursos que articulan y legislación. La interpretación de las fuentes utilizadas para sugerir que los debates y las reenvía todo el coeducación fueron centrales en el proceso de feminización de la profesión docente. Alrededor de ellos, un número creciente de personas, ya sean funcionarios, profesores e intelectuales se pusieron en defensa del trabajo de las mujeres en la enseñanza primaria, lo que lleva a la creación de las bases jurídicas que garantizaban/estimulaban el trabajo femenina en las escuelas.

Palabras-clave: educación en Brasil, siglo 19, coeducación, feminización de la enseñanza, legislación educativa.

\section{LE PROCESSUS DE FEMINISATION DE L'ENSEIGNEMENT AU BRESIL DU SIECLE 19: CO-EDUCATION OU ECOLES MIXTES}

\section{Résumé}

L'etude a comme proposition comprende le processus de feminisation de l'enseignement basée sur sa rélation avec l'éducation mixte. Pourtant, l'analyse de certains discours des intellectuels, professeurs et autorités qui ont defendu la pratique de l'éducation mixte dans des écoles publiques primaires et cherche à démontrer comme tels discours faisaient écho dans la société, apportant sa matérialisation dans la éducationnelle à partir du milieu du $19^{\text {éme }}$ siécle. Le texte apporte une comparaison entre les actions mises em oeuvre sur le terrain dans des provinces de Rio de Janeiro, Mato Grosso et Paraná. Articulant les discours et la législation. L'interprétation des sources utilisées permet d'affirmer que les démarches autour de l'éducation mixte furent élement centrales pour le processus de féminisation de l'enseignement. Autour d' eux, chaque fois un grand nombre des individus, soit eux les autorités,professeurs et intéllectuels se sont mis en défense du travail des femmes dans l'enseignement primaire, portant la construction des bases légales qui garantent/ estimulent le travail feminin dans des écoles.

Mots-clé: l'éducation au Brésil, siecle 19, l'éducation mixte, feminisation de l'enseignement, légalisation éducationnelle. 


\section{Introdução}

$\mathrm{N}$ os últimos anos, em virtude do expressivo aumento da pós-graduação em Educação, houve um grande incremento nas pesquisas e, dentre os muitos campos de pesquisas que perpassam pela educação, a História da Educação tem se destacado. Na História da Educação a temática da feminização do magistério é objeto de estudos de muitos pesquisadores. Dentre tantos, cito Almeida (1998), Faria Filho e Macedo (2004), Hahner (2011). Diante da expressiva produção sobre o tema e da diversidade de objetos e de abordagens, autores como Sá e Rosa (2004) e Gondra e Schueler (2008) se ocuparam em fazer estudos analíticos da produção sobre o tema e constataram que os estudos privilegiam as questões relacionadas ao mercado de trabalho, relações de gênero e ao processo de escolarização.

Sá e Rosa (2004) enquadraram a produção analisada em quatro eixos: alterações no mercado de trabalho associado ao avanço do capitalismo; incremento no processo de escolarização com o aumento do número de matrículas de meninas; mudanças na mentalidade/representação enfatizando o magistério como ocupação feminina; protagonismo feminino na ocupação de um emergente mercado de trabalho.

Dentre o conjunto de estudos sobre a feminização do magistério as questões relacionadas à coeducação ou escolas mistas têm sido pouco estudadas no Brasil. Do conjunto de estudos sobre o tema cito Lopes (1999) e Hahner (2011), que se utilizam de fontes do período, mas, no geral, a maioria dos estudos sobre o tema não estão respaldados em fontes de época. O presente estudo, centrado no século 19, parte da análise dos discursos de intelectuais, professores e autoridades que defendiam a difusão da coeducação nas escolas públicas primárias e demonstra como tais discursos fizeram eco na sociedade, levando à sua materialização na legislação educacional a partir de meados do século 19. O estudo está pautado em análise comparativa entre as ações implantadas na Corte e nas províncias do Rio de Janeiro, Mato Grosso e Paraná.

As fontes analisadas permitem afirmar que os debates e encaminhamentos em torno da coeducação foram elementos centrais para o processo de feminização do magistério. Em torno deles um número cada vez maior de indivíduos, sejam eles autoridades, professores e intelectuais se dispuseram à defesa do trabalho das mulheres no magistério primário, levando à construção de bases legais que garantiram ou estimularam o trabalho feminino nas escolas.

Entre as fontes utilizadas destacam-se a legislação educacional das quatro unidades administrativas, relatórios de presidentes de províncias, de inspetores de instrução pública, de comissões de inspeção, escritos de professores, de autores do século 19 e de historiadores da educação. Amparado pela documentação do período organizei o texto em três partes. Na primeira apresento os discursos em defesa da coeducação; na segunda demonstro como a coeducação foi sendo garantida e efetivada na legislação educacional; na terceira apresentam-se dados que expressam o crescimento das escolas femininas e, consequentemente, o número de professoras e a crescente participação das mulheres nas escolas normais. 


\section{A coeducação nos discursos de intelectuais, professores e autoridades}

Em regra geral a coeducação no Império foi bastante insipiente. Até 1870 as experiências praticamente não existiram na rede pública, mas depois de então se tornaram mais constantes, apesar de apresentarem várias restrições no seu caráter prático devido ao alto grau de moralidade e religiosidade presentes na sociedade.

As fontes indicam que o movimento em defesa da coeducação ou das escolas mistas ganhou força, na medida em que as escolas femininas foram sendo criadas nas vilas e cidades de forma mais constante a partir de 1850. Influenciados pelo sucesso do modelo norte-americano e de vários países da Europa, muitos intelectuais, professores e autoridades passaram a defender a introdução da experiência nas escolas públicas brasileiras, pois nas escolas particulares já havia uma prática mais efetiva. Uma das primeiras personalidades de destaque a defender tal modelo de educação foi Tavares Bastos. No livro A província, publicado em 1870, propôs o seguinte:

Como nos Estados Unidos, o ensino devera nos campos ser o mesmo que nas cidades; geral, sem distinção de territórios; geral ainda, sem distinção de sexos. Ambos os sexos, nas mesmas casas, simultaneamente, receberiam a mesma instrução. E não recomendamos as escolas mistas pela economia somente, que aliás é considerável no ensino comum dos dois sexos; mas principalmente pelo magnífico estimulo e fecundos efeitos morais da união dos dois sexos desde a infância. $(1975, \text { p. } 156)^{2}$

Nas conferências pedagógicas realizadas em janeiro de 1873, da qual participaram autoridades, professores públicos e particulares, o tema da coeducação ou escolas mistas foi intensamente debatido. Ele figurou como terceiro ponto dos cinco previstos para o evento, com o seguinte título: "se convém ou não a instituição das escolas mistas de instrução primária?" (Brasil. Atos do Ministério do Império de 1872). O principal defensor da matéria foi o professor interino Antônio Estevam da Costa Cunha, que apresentou a conferência Coeducação dos sexos, no dia 18 de janeiro de 1873. Baseando-se na experiência norteamericana enfatizou as vantagens advindas da implantação das escolas mistas:

$1^{\circ}$ comodidade para as famílias que mandam seus filhos para um mesmo estabelecimento, e não para dois de diferente sexo, às vezes em grande distância um do outro. $2^{\circ}$ continuação da vida da família por irmãos e irmãs na mesma escola, cada qual feliz pela presença do outro e servindo-se mutuamente de apoio. $3^{\circ}$ maior emulação nos estudos, não querendo um dos sexos fazer triste figura diante do outro. (Cunha, 1873, p. 1)

Costa Cunha (1873), apoiando-se no relatório do inspetor de instrução pública, João José Pinto Junior da Província de Pernambuco, associou a difusão das escolas mistas com o trabalho das mulheres no magistério. Por isso, defendeu a criação de escolas normais femininas. Se a escola era o "elemento com que contamos para fazer a nossa pátria grande e respeitada, a escola dirigida pela mulher com a necessária instrução e moralidade, é a

${ }^{2}$ Nas citações optei por atualizar a grafia para os padrões atuais respeitando, todavia, a pontuação e os destaques presentes nos textos. 
escola no seu máximo de perfeição". Assim "cumpre, pois, sem perda de tempo, ir habilitando as senhoras para tão elevado mister para que cheguemos a conseguir aquela desejada perfeição" (Cunha, 1873, p. 2). Nessa perspectiva, propôs que se autorizasse

desde já a entrada de meninos até aos 7 anos nas escolas do sexo feminino, os quais se poderão demorar nelas até a idade de 10 anos, sendo as pessoas encarregadas das ditas escolas rigorosamente obrigadas a remeterem para a mais próxima escola do sexo masculino qualquer menino que manifeste qualidades que possam tornar nociva ali sua presença, ou melhor que comunique imediatamente o fato à inspetoria geral para esta providência como for de mister. (1873, p. 4)

Apesar de propor a frequência até 10 anos, deixou bem claro que a entrada só se daria até os 7 anos, assim os alunos iriam acostumando-se a convivência e não trariam perigo à moralidade. Na medida em que a experiência fosse se consolidando, poderia ampliar a idade de permanência mista nas escolas. Na sua concepção a introdução da experiência no Brasil deveria se dar nas escolas femininas e justificou a medida da seguinte forma:

Como instituidor primário, o homem ou é ou não é ilustrado; se é, suas tendências são para o ensino mais elevado e não para o de criancinhas que ainda necessitam do regaço materno, avizinhas implumes que não podem dispensar o calor das asas de seus progenitores; se não é, se gira somente na assanhadíssima esfera do a b c, então não convém para tomar sobre si $a$ delicadíssima missão de preceptor. (Cunha, 1873, p. 4-5)

Nas mesmas conferências um grupo de professores, tendo como relator Manuel José Pereira Frazão, concordou que o "ensino dado simultaneamente a ambos os sexos concorre poderosamente para o desenvolvimento da nação" (Breves, 1873, p. 23). Mas alertaram aos participantes de que "cumpre porém, não confundir a proposição absoluta com sua aplicação à nossa sociedade, onde ela só poderá produzir, ao menos por enquanto, males consideráveis" (p. 23). Segundo eles a sociedade brasileira não estava preparada para a implantação das escolas mistas, pois,

desde a mais tenra idade nota-se uma tendência para a sensualidade, a qual não encontrando barreira nos exemplos da educação doméstica, que são péssimas, salvando honrosas exceções, nem nos sentimentos religiosos, que quase não existem, deve concorrer para estragar cada vez mais, em lugar de edificar a mesma sociedade. Não nos iludamos: por em contato com meninas de famílias recatadas, meninos cheios de maus costumes, é querer apressar a sua perdição. (Breves, 1873, p. 23)

${ }^{3} \mathrm{O}$ documento tem a data de 17 de janeiro de 1873 e foi assinado por nove professores: Antônio José Marques, Carlos Antônio Coimbra de Gouvêa, João José Moreira, Joaquim Fernandes da Silva, José Antônio de Campos Lima, José Bernardes Moreira, José João de Povoas Pinheiro, José Joaquim Xavier e Manuel José Pereira Frazão (Breves, 1873, p. 26). 
O grupo de professores propôs iniciar a experiência, criando "asilos mistos, em que as crianças se habituem a viver em contato enquanto são inocentes" (1873, p. 23). Mesmo assim apresentaram restrições, devido ao nível de formação das mulheres brasileiras. Segundo eles a "maior parte das que se dizem instruídas porque traduzem mal o francês e tocam piano de ouvido, carecem das noções mais rudimentais dos conhecimentos úteis" (Breves, 1873, p. 23).

Antônio de Almeida Oliveira, em seu escrito publicado em 1873, se posicionou em favor da coeducação. Afirmou ele que se o Estado desejava fazer uma "reformar completa e eficazmente" no ensino público deveria "abolir a distinção de escolas para meninos e escolas para meninas" e estabelecer escolas de frequência comum. Justificou a proposta com argumentos de ordem econômica, moral e política. As vantagens econômicas estavam ligadas a redução do número de escolas e de professores, pois na maioria das vilas a frequência das duas escolas não era superior a 60 alunos e, portanto, poderia ser ofertada em apenas uma escola. Segundo ele a coeducação traria vantagens morais, "longe de ser um mal é um bem", pois a convivência garantiria que os "costumes de uns e outros se conservam puros e isentos daquela malícia, que produz a separação dos sexos, ou a ideia de que sua aproximação é um perigo misterioso e inevitável". As vantagens políticas estavam associadas à facilidade de organização da instrução, sua generalização e os "costumes mais amigáveis e doces" (Município da Corte, 2003, p. 115).

A proposta de escolas mista defendida por Almeida Oliveira não se restringia, apenas, às crianças: "As mesmas razões de economia na despesa, estímulo nos alunos e igualdade nos benefícios da instrução exigem que as escolas normais sejam comuns a um e outro sexo" (Município da Corte, 2003, p. 214). A defesa de escolas normais mistas era inovadora à época. Já havia escolas normais femininas, mas funcionavam em dias alternados às dos homens.

Almeida Oliveira defendeu a preponderância das mulheres para trabalhar com a educação primária, principalmente na primeira etapa da educação das crianças. Segundo ele, "o homem ordinariamente não possui a paciência e a bondade que as crianças precisam achar em que trata com elas". Já a mulher "sabe empregar a carícia para despertar a alma, e a simpatia para dirigir-Ihe os primeiros voos". Para reforçar o seu posicionamento enfatizou que

a mulher não faz só o menino interessar-se pela lição e aprendê-la depressa. Mais penetrante que o homem, ou conhecendo melhor que ele o coração humano, especialmente o dos meninos, a mulher ataca suas inclinações pelo lado conveniente e comunica-lhe a um tempo a elevação, a pureza e a brandura do seu espírito. (Município da Corte, 2003, p. 206)

Assim, continuou ele, o que a mulher "faz pela afeição o homem faz por meio de regulamentos e sistemas repressivos. $O$ que não consegue nem a ameaça nem a fria lógica do homem, consegue uma tenra advertência da mulher". Na sua concepção o magistério feminino era o "mais poderoso auxiliar do evangelho" (Município da Corte, 2003, p, 206). 
No relatório da comissão encarregada de fazer uma avaliação geral das escolas da Corte, entre 1873 e 1874, encontrei uma prova muito significativa sobre a prática da coeducação. Segundo o referido documento,

em algumas escolas de meninas são recebidos meninos contra o disposto na lei. A comissão consigna aqui este fato por ser uma transgressão do regulamento respectivo, mas entende que seria de suma vantagem o permitirse a entrada de meninos de boa educação e de idade menor de 8 anos, nas escolas do sexo feminino, tomando-se as competentes cautelas, para evitar qualquer quebra de moralidade (Município da Corte, 1873, p. 53).

De fato, a ação das professoras era ilegal, visto que o regulamento de 1854 não autorizava tal modalidade de ensino. Mas como ficou explicito no fragmento, a comissão também apoiou a iniciativa. Esta passagem evidencia que a experiência da coeducação já ocorria, na Corte antes da Reforma Leôncio de Carvalho de 1879.

Em Mato Grosso, o inspetor de instrução pública Dermevil José dos Santos Malhado justificou a superioridade das mulheres para o magistério com os seguintes argumentos:

A mulher tem qualidades especiais para educadora e mestras; é muito superior ao outro sexo em clareza, doçura, imaginação, paciência, bondade, zelo e graça, o que constitui para com as crianças, sempre saudosas do carinho materno, uma espécie de atração para a professora, sujeitando-se elas as imposições do estudo, unicamente para satisfazê-la. (Província de Mato Grosso. Inspetoria Geral. Relatório de 1880, p. 8)

Uma das principais autoridades a defender a adoção das escolas mistas na Corte foi o inspetor Antônio Herculano de Souza Bandeira Filho. Antes de ser inspetor Souza Bandeira havia sido encarregado de fazer um estudo sobre a realidade educacional, da Europa e dos Estados Unidos, para servir de base à implantação de reformas no sistema brasileiro. Assim, logo que assumiu a inspetoria sugeriu ao ministro do Império que nomeasse professoras para reger as duas cadeiras para o sexo masculino, que se encontravam vagas. Ao ser aceita a proposta pelo ministro, o inspetor fez a seguinte afirmação: "Espero que esta providência, generalizada como deve ser, concorrerá para melhorar o nosso ensino primário, despertando no sexo feminino vocações aproveitáveis, e abrindo mais amplos horizontes a atividade de nossas inteligentes patrícias" (Município da Corte. Inspetoria Geral. Relatório de 1884, p. 23). Por sua vez, José Ricardo Pires de Almeida sintetizou as vantagens da escola mista em 1889, da seguinte forma:

No país onde o sistema misto é comum, seu público reconhece as seguintes vantagens: $1^{\circ}$ ) grande comodidade para os pais que enviam seus filhos juntos para um mesmo estabelecimento e não para dois diferentes, situados às vezes longe um do outro; $2^{\circ}$ ) continuação da vida familiar para os irmãos e irmãs reunidos em uma mesma escola; $3^{\circ}$ ) emulação maior entre as crianças; $4^{\circ}$ ) aquisição de bons hábitos desde a primeira juventude, tanto para os meninos quanto para as meninas; $5^{\circ}$ os fatos que se quer prevenir, pela 
segregação dos sexos e a vigilância incessante, são muito mais raros nos países onde a educação é dada em comum do que naqueles onde o sistema misto não existe. (1989, p. 154)

Fica evidente, pelo conjunto de posicionamentos, a ampla defesa da coeducação ou escolas mistas e das qualidades das mulheres para o exercício da função de professoras primárias. Vejamos como esse conjunto de discursos foi incorporado na legislação educacional.

\section{As bases legais para a difusão da coeducação}

Do conjunto da documentação e legislação que tive a oportunidade de comparar a primeira referência relacionada às escolas mistas apareceu no projeto de organização da instrução nacional, apresentado pela Comissão de Instrução Pública da Câmara dos Deputados, em 1826, conhecido como Projeto Januário da Cunha Barbosa. Segundo o artigo $6^{\circ}$ do referido projeto "as meninas serão igualmente admitidas com os meninos nas escolas de primeiro grau; a sua instrução será a mesma e simultânea" (Anais da Câmara, 1826, p. 151). A medida proposta não passou de projeto. Em seu lugar foi aprovada a lei de 15 de outubro de 1827, que estabeleceu escolas separadas para meninos e meninas.

A primeira referência legal encontrada foi a do Regulamento de 1846, da Província de São Paulo, que determinou, no artigo $8^{\circ}$, que "a frequência promíscua de ambos os sexos em uma escola, só é permitida nos lugares, onde não existam escolas diversas para ambos" (Província de São Paulo. Lei n. 34, de 1846). Apesar de estar previsto na legislação, tudo indica que na prática não chegou a vigorar, pois não encontrei dados entre as fontes consultadas.

Outra referência legal às escolas mistas ou coeducação apareceu no artigo 114 do regulamento de 8 de abril de 1857, da Província do Paraná nos seguintes termos: "O governo poderá criar nas principais localidades da Província, casas de asilo para a instrução promíscua de indigentes e pagantes" (Miguel, 2000, p. 35). Pelas informações disponíveis nos relatórios posteriores, não há referencias sobre a existência de tais instituições na Província.

A primeira referência mais objetiva apareceu no artigo 60 do regulamento de 24 de dezembro de 1859, da Província do Rio de Janeiro. Segundo o referido artigo, nas escolas de meninas poderiam "ser admitidos meninos até a idade de 7 anos, e frequentá-la até a de 8 por mútuo acordo dos pais e das professoras" (Província do Rio de Janeiro. Regulamento de 1859). O mesmo texto foi mantido no artigo 64 do regulamento de 30 de abril de 1862 (Província do Rio de Janeiro. Regulamento de 1862). A lei deixava bem claro que somente era permitida a frequência de meninos nas escolas de meninas e mediante acordo entre pais e professoras. No caso da Província do Rio de Janeiro existiam as escolas da colônia alemã de Petrópolis, cujos resultados eram elogiados pelos inspetores, dentre as quais algumas eram mistas. 
No Paraná as escolas mistas certamente existiram nas diversas colônias de imigrantes que se estabeleceram no território a partir de meados do século 19. Mas as primeiras iniciativas oficiais só apareceram em 1874, quando iniciou-se a criação de escolas mistas ou promíscuas.

Por exemplo, os decretos n. 396, 398, 399 e 400, de 11 de abril, de artigo único determinavam o seguinte: "Fica criada uma cadeira de instrução primária promíscua (masculina ou feminina) no [...], onde o Governo achar conveniente, revogada as disposições em contrário" (Miguel, 2000, p. 178-82).

Pelos decretos as escolas mistas - promíscuas - poderiam ser masculinas ou femininas. Essa dubiedade foi corrigida no regulamento de 16 de julho de 1876 quando, no artigo 103, que tratava das proibições aos professores públicos, foi proibido ao professor "lecionar alunos de sexo diferente. As professoras não estão compreendidas neste §, podendo lecionar menores até a idade de 10 anos" (Miguel, 2004, p. 276). Ao considerar tal artigo deve-se entender que as escolas promíscuas masculinas ou femininas seriam regidas por professoras. Por ato de 26 de setembro de 1877, da província do Paraná, foi convertida a maioria das escolas localizadas nas vilas e freguesias em escolas promíscuas. $E$, de acordo com o artigo $2^{\circ}$, a "disposição do artigo antecedente que converte em promíscuas algumas cadeiras do sexo masculino, só se fará afetiva para aquelas que estiverem atualmente vagas" (Miguel, 2004, p. 293). Diante de tal decisão fica evidenciado que as escolas masculinas vagas ou que vagassem, só poderiam ser regidas por professoras.

Na Província do Rio de Janeiro o regulamento de 16 de dezembro de 1876, pelo artigo 37, estabeleceu que

nas freguesias em que as duas escolas não tenham a frequência legal, ou uma tenha e outra não, poderá o presidente da província dar a uma delas o caráter de escola mista, em que matriculem alunos de um e outro sexo. $\S 1^{\circ}$ Para a regência dessas escolas serão preferível as professoras. $\S 2^{\circ}$ quando for absolutamente impossível a preferência, poderão se regidas por professores, com tanto porém que sejam casados e vivam em companhia de suas mulheres. $\S 3^{\circ}$ No regimento das escolas se estabelecerão as regras para a entrada e saída dos alunos, separação na sala da escola, serviço interno, e para tudo o mais que se julgar conveniente. $\S 4^{\circ}$ Ficam excetuadas as atuais escolas da cidade de Petrópolis, em que a matrícula e frequência já são mistas. (Província do Rio de Janeiro. Regulamento de 1876, p. 288-9)

A primeira permissão legal na Província de Mato Grosso apareceu no regulamento de 13 de fevereiro de 1878. O artigo 114 a autorizou nos seguintes termos:

Nas paróquias ou localidades, em que não houver escola pública para meninas, poderão nestas ser admitidas a matrícula na escola do sexo masculino por acordo entre os pais ou tutores das meninas e os respectivos Inspetores Paroquiais, e o Presidente da Província poderá, de preferência, prover tais cadeiras de Professora, ainda quando o número dos alunos exceda ao das alunas. (Sá; Siqueira, 2000, p. 133) 
Porém, segundo o novo regulamento, expedido em 4 de março de 1880, no artigo $12 \S$ 17 , as professoras estavam autorizadas a receber meninos até a idade de 10 anos (Sá; Siqueira, 2000, p. 152).

$\mathrm{Na}$ Corte, a oficialização das escolas mistas regidas por mulheres apareceu no $\S 3^{\circ}$ do artigo $4^{\circ}$, do decreto n. 7.247 , de 19 de abril de 1879, a chamada reforma Leôncio de Carvalho. O respectivo parágrafo determinou o seguinte: "Nas escolas do $1^{\circ}$ grau existentes, ou que se fundarem para o sexo feminino serão recebidos alunos até a idade de 10 anos" (Brasil. Decreto 7.247 de 1897, p. 198). Já pelo Regimento Interno das Escolas Primárias da Corte, expedido em 6 de novembro de 1883, ficou estabelecido, no artigo 16, que as crianças menores de 6 anos, só poderiam frequentar as escolas femininas e o artigo 17 determinou que "as crianças do sexo masculino, desde a idade de 6 até a de 10 anos, poderão ser admitidas à matrícula nas escolas de meninas, e aí permanecerem até ficarem prontas para a $2^{a}$ classe, dentro do limite de idade" (Brasil. Decisão n. 77 do Ministério do Império de 1883, p. 79).

No projeto de reforma da instrução, resultante dos pareceres da comissão da Câmara dos Deputados, cujo relator foi Rui Barbosa, a questão foi apresentada da seguinte forma no artigo $2^{\circ}$, do título Da educação primária pública e seu magistério:

$X V$. As escolas elementares e médias que o governo declarar mistas, receberão indiferentemente alunos de um e outro sexo, não maiores de onze anos. XVI. As escolas mistas, bem como os jardins de crianças e as escolas do sexo feminino, serão exclusivamente dirigidas por pessoas deste sexo. As escolas elementares do sexo masculino poderão ser indistintamente confiadas a professores ou professoras. (Barbosa, 1947, p. 95)

A proposta de Rui Barbosa não passou de projeto, mas contribuiu para orientar os encaminhamentos futuros. No primeiro regulamento do período republicano, elaborado por Benjamim Constant, a questão foi resolvida da seguinte forma: segundo o previsto no artigo $2^{\circ}$, no seu $\S 1^{\circ}$, "as escolas do $1^{\circ}$ grau admitirão alunos de 7 a 13 anos de idade, e as do $2^{\circ}$ grau, de 13 a 15 anos. Umas e outras serão distintas para cada sexo, porém meninos até 8 anos poderão frequentar as escolas do $1^{\circ}$ grau do sexo feminino" (Brasil. Decreto n. 981 de 1890 , p. 3475). Pelo artigo $7^{\circ}$ definiu-se os encaminhamentos de forma mais clara:

As escolas do $1^{\circ}$ grau para o sexo masculino serão dirigidas de preferência por professoras no primeiro curso, e por professores no $2^{\circ}$ e $3^{\circ}$ cursos, respectivamente auxiliados por adjuntas ou adjuntos; as escolas do $1^{\circ} \mathrm{grau}$ para o sexo feminino só o serão por professoras em todos os seus cursos; nas escolas do $2^{\circ}$ grau, porém, será o magistério exercido por professores ou professoras, conforme o sexo a que a escola se destinar. (Brasil. Decreto $n$. 981 de 1890, p. 3476-7)

Apesar de haver bases legais para a difusão da coeducação, as resistências a sua efetivação no cotidiano escolar se mantinham ainda muito fortes no final do século 19. Várias escolas eram mistas, mas tomavam-se todas as providências para evitar o contato entre os 
sexos. Isso evidencia como os aspectos morais e religiosos emperraram o desenvolvimento da instrução pública no país. Valores e preconceitos enraizados por toda a sociedade viam no contato entre meninos e meninas uma séria ameaça à ordem e a moral pública.

\section{Escolas normais: uma porta para a emancipação feminina}

Pelo relatório de Almeida Oliveira (Município da Corte, 2003), em 1873 havia escolas normais em 10 províncias. A falta em algumas delas poderia ser atribuída "à exiguidade dos recursos, noutras à incúria dos legisladores: em nenhuma a defeito da ideia, pois nunca a experimentaram" (p. 213). Na concepção do autor o magistério era um ofício, "logo quem quiser segui-lo deve conhecê-lo" (Município da Corte, 2003, p. 211). Assim, sua obra constituiu-se em um instrumento de defesa das escolas normais e, principalmente, do trabalho das mulheres no magistério. Suas ideias, e de muitos outros aliados, se disseminaram pelas províncias.

Já na década de 1870 algumas das escolas normais existentes eram mistas, por exemplo, a da Província do Rio de Janeiro e a de Mato Grosso, mas funcionavam em dias alternados, evitando o contato entre os sexos. Na Província do Rio de Janeiro houve a tentativa de separar as escolas em 1876, mas devido à falta de candidatas habilitadas para dirigir as cadeiras o projeto não teve êxito, voltando ao estado anterior. Em 1880 houve uma nova reforma instituindo a escola normal mista de frequência promíscua, mas com uma severa vigilância, permitindo o contato entre os sexos somente na sala de aula.

Tais medidas se mostraram eficientes e estimularam o ingresso das mulheres no magistério, segundo indicou o relatório da comissão encarregada de fazer uma avaliação geral da instrução na Província no ano de 1882. Ao se referir à Escola Normal emitiram o seguinte parecer:

Parece à comissão que o fato constante de ser a Escola Normal mais procurada por alunas do que por alunos, além de ser para o estabelecimento motivo justo de desvanecimento, indica que em próximo futuro a instrução e educação da infância será confiada em sua máxima parte a professoras, que certamente foram dotadas pela Providencia com as qualidades mais apropriadas para o desempenho dessa tarefa. A comissão faz votos para que essa evolução se realize, e tem esperança que o governo, sem empregar meios diretos, saberá dar a direção conveniente para que não seja iludida (Província do Rio de Janeiro. Relatório da Comissão, 1882, p. 34)

A escola normal criada na Corte em 1880 também funcionava de forma mista. Em 1884, ao se referir a tal instituição, Antonio Herculano de Souza Bandeira, inspetor de instrução pública da Corte, afirmou que "apesar dos defeitos da atual Escola Normal, as suas alunas que ocupam lugares no magistério distinguem-se por conhecimentos sólidos e por maior dedicação a carreira" (Município da Corte. Inspetoria Geral. Relatório de 1884, p. 57). Além de estar crescendo a procura pelas escolas normais por parte das mulheres, a maioria delas apresentava, aos olhos das autoridades, resultados mais satisfatórios que dos homens.

Para demonstrar a ascensão das mulheres no processo educacional ao longo do Império organizei alguns dados apresentados no quadro a seguir. 
Tabela 1 -

Participação feminina em porcentagem no número total de alunos e como professoras das escolas públicas da Corte, Província do Rio de Janeiro, Mato Grosso e Paraná, entre 1837 e 1889.

\begin{tabular}{|c|c|c|c|c|c|c|c|c|c|}
\hline \multicolumn{9}{|c|}{ Município da Corte } & \multicolumn{5}{c|}{ Província do Rio de Janeiro } \\
\hline Ano & $\begin{array}{c}\text { T. de } \\
\text { Alunos }\end{array}$ & Meninas & $\%$ alunas & N. prof ${ }^{a}$ & Ano & $\begin{array}{c}\text { T. de } \\
\text { Alunos }\end{array}$ & Meninas & $\%$ alunas & N. profa. \\
\hline 1839 & 1.316 & 340 & 25.83 & 6 & 1837 & 664 & 65 & 9.78 & 2 \\
\hline 1854 & 1.464 & 555 & 37.90 & 9 & 1856 & 5.136 & 1.345 & 26.18 & 58 \\
\hline 1870 & 4.383 & 1.903 & 43.41 & 21 & 1872 & 9.690 & 2.921 & 30.14 & 155 \\
\hline 1888 & 9.021 & 4.122 & 45.69 & 48 & 1887 & 19.123 & 6.895 & 36.05 & 166 \\
\hline \multicolumn{6}{|c|}{ Província de Mato Grosso } \\
\hline 1854 & 417 & 18 & 4.31 & 2 & 1856 & 1.324 & 453 & 34.21 & 11 \\
\hline 1874 & 1.248 & 300 & 24.03 & 6 & 1872 & 1.951 & 609 & 31.21 & 31 \\
\hline 1889 & 1.479 & 516 & 34.88 & 12 & 1887 & 4.506 & 1.659 & 36.81 & ${ }^{*} 39^{4}$ \\
\hline
\end{tabular}

Fonte: Dados organizados a partir dos relatórios do Ministério do Império, dos presidentes de províncias e de inspetores de instrução pública, dos respectivos anos.

Os dados mostram um crescimento considerável da participação feminina não só como alunas, mas também como professoras em todas as unidades administrativas comparadas. Para exemplificar ainda mais, exponho dados da matrícula nas escolas normais da Província do Rio de Janeiro e da Corte.

Tabela 2 -

Frequência de homens e mulheres nas escolas normais da Província do Rio de Janeiro e na Corte, entre 1870 a 1888.

\begin{tabular}{|c|c|c|c|c|c|}
\hline \multicolumn{3}{|c|}{ Província do Rio de Janeiro } & \multicolumn{3}{c|}{ Município da Corte } \\
\hline Ano & Homens & Mulheres & Ano & Homens & Mulheres \\
\hline 1870 & 19 & 15 & 1870 & - & - \\
\hline 1880 & 18 & 34 & 1881 & 105 & 177 \\
\hline 1886 & 41 & 79 & 1886 & 76 & 255 \\
\hline 1888 & 61 & 116 & 1888 & 64 & 268 \\
\hline
\end{tabular}

Fonte: Dados organizados a partir dos relatórios dos diretores das escolas normais e dos inspetores de instrução pública, dos respectivos anos.

Não resta dúvida que o maior número de alunos que procuravam a escola normal era de mulheres, mas não nos iludamos com os números, pois os concluintes ainda eram muito poucos. Por exemplo: na escola da Corte, dos 331 alunos do ano de 1886, 240 matricularamse na primeira série, mas apenas nove concluíram o curso de $1^{\circ}$ grau, de duração de 2 anos,

\footnotetext{
${ }^{4}$ Havia 59 escolas classificadas como promíscuas, que pela lei seriam prioritariamente regidas por mulheres. 
no final de 1887, sendo 7 mulheres (Brasil. Relatório do Ministro do Império de 1888, p. 30). Já, na Escola Normal da Província do Rio de Janeiro formaram-se 21, sendo 13 mulheres (Província do Rio de Janeiro. Diretoria da Instrução. Relatório de 1888, p. 21).

$\mathrm{Na}$ Escola Normal da Corte a frequência era livre, em virtude da reforma Leôncio de Carvalho ter instituído tal prática. Diante disso, um grande número de alunos se escrevia para a primeira série, mas não se dedicava ao curso. Para resolver esse inconveniente o governo reformou a escola, pelo decreto n. 10.060, de 13 de outubro de 1888, procurando dar um caráter mais profissional e especifico. Conforme o artigo 86 os alunos que desejavam ingressar na escola deveriam apresentar os seguintes documentos no momento da inscrição: certidão provando idade entre 16 e 22 anos, atestado de moralidade passado pelo pároco, ou por pessoa conceituada, reconhecida por tabelião, atestado de saúde emitido pela inspetoria de higiene, provando ter sido vacinado, atestado de identidade passado por um professor da escola. Segundo o artigo 87, o inspetor de instrução pública poderia indeferir a inscrição, mesmo diante da apresentação dos atestados (Brasil. Decreto n. 10.060 de 1888, p. 18). Assim, a reforma instituiu uma espécie de vestibular para o ingresso na escola, limitando a entrada em 50 alunos por ano e impondo a frequência obrigatória. Tal reforma, conforme indicou o relatório do ministro Antônio Ferreira Vianna, de 1889, provocou um intenso debate na imprensa e muitas demissões na escola (Brasil. Relatório do Ministro do Império de 1889, p. 25-28). Mas, certamente, a medida garantiu um caráter mais profissional e moderno ao processo de formação de professores a partir de então.

\section{Conclusões}

Ao olharmos para as medidas adotadas no século 19 para coibir ou estimular a coeducação percebe-se que a riqueza da história está em captar as diversas ideias, propostas e ações práticas produzidas por homens e mulheres que viveram antes de nós, as quais permitem compreender o estágio atual do desenvolvimento educacional, pois, o que praticamos hoje é o resultado da soma dos acertos e fracassos, das muitas ações praticadas pelas gerações que nos precederam. Assim, cabe ao historiador ver e analisar as ações dos homens do passado a partir de seu contexto, de suas crenças e valores, ou seja, dentro de seus limites históricos.

Diante do exposto, concluo que os discursos produzidos por professores, intelectuais e administradores em defesa da coeducação foram centrais para construir bases legais que estimularam a feminização do magistério e difusão das escolas normais femininas. É possível afirmar que a introdução das escolas mistas interferiu no processo de feminização do magistério, estimulou a criação de escolas normais femininas e, ao mesmo tempo, impôs mudanças na base legal, favorecendo o ingresso das mulheres no magistério. A partir disso, sustento a tese de que, no Brasil, as questões relacionadas ao processo de difusão da coeducação tiveram bem mais força no processo de feminização do magistério do que as transformações na base capitalista relacionada à divisão social do trabalho, ou seja, naquele contexto, as questões relacionadas à moralidade e a religiosidade - alicerces da cultura da época - tiveram mais peso no processo de feminização do magistério do que as transformações na base produtiva. 
Diante disso, é possível concluir que a preocupação com o trabalho estava mais voltado ao potencial moral do que científico, ou seja, interessava mais o educar pelo exemplo do que o instruir pela ciência. Assim, as mulheres também cumpriram um importante papel na difusão de uma concepção de sociedade, fundamentada na ordem, na moralidade, centrais no projeto civilizatório do Brasil do século 19. As professoras e, ao mesmo tempo, o trabalho exercido por elas servia de espelho/luz às crianças, futuros cidadãos.

\section{Referências}

ALMEIDA, Jane Soares de. Mulher e educação: a paixão pelo possível. São Paulo: Unesp, 1998.

ALMEIDA, José Ricardo Pires de. História da instrução pública no Brasil (1500-1889): história e legislação. São Paulo: Educ; /Brasília: Inep, 1989.

BARBOSA, Rui. Reforma do ensino primário e várias instituições complementares da instrução pública. Vol. X, Tomo IV. Rio de Janeiro: Ministério da educação e Saúde, 1947.

BASTOS, Aureliano Cândido Tavares. A província: estudo sobre a descentralização no Brasil. São Paulo: Nacional, 1975.

BRASIL. Anais da Câmara dos Deputados de 16 de junho de 1826. Disponível em <http://imagem.camara.gov.br/dc_20b.asp?selCodColecaoCsv=A\&Datain=16/6/1826>.

Acesso em 15 jan. 2014.

BRASIL. Lei de 15 de outubro de 1827. Manda criar escolas de primeiras letras em todas as cidades, vilas e lugares mais populosos do Império. Coleção das Leis do Império do Brasil de 1827 - primeira parte. Rio de Janeiro: Tipografia Nacional 1878.

BRASIL. Decreto n. 7.247 de 19 de abril de 1879. Reforma o ensino primário e secundário no município da Corte e o superior em todo o Império. Coleção das Leis do Império do Brasil de 1879. Rio de Janeiro: Tipografia Nacional, 1880.

BRASIL. Decisão n. 77 do Ministério do Império de 6 de novembro de 1883. Aprova o regimento interno para as escolas públicas primárias do $1^{\circ}$ grau do município da Corte. Coleção das Decisões do Governo do Império do Brasil de 1883. Rio de Janeiro: Tipografia Nacional, 1884.

BRASIL. Relatório do Ministro dos Negócios do Império, José Fernandes da Costa Pereira Junior. Apresentado à Assembleia Geral Legislativa, em 3 de maio de 1888. Rio de Janeiro: Tipografia Nacional, 1888.

BRASIL. Decreto n. 10.060 de 13 de outubro de 1888. Dá novo Regulamento à Escola Normal. Coleção das Leis do Império do Brasil de 1888. Rio de Janeiro: Tipografia Nacional, 1889.

BRASIL. Relatório do Ministro dos Negócios do Império, Antônio Ferreira Vianna. Apresentado à Assembleia Geral Legislativa, em 15 de maio de 1889. Rio de Janeiro: Tipografia Nacional, 1889.

BRASIL. Decreto n. 981 de 8 de novembro de 1890. Aprova o Regulamento da Instrução Primaria e Secundaria do Distrito Federal. Decretos do Governo Provisório da República dos Estados Unidos do Brasil de 1890. Imprensa Nacional, 1891. 
BREVES considerações que fazem os professores abaixo assinados sobre os pontos marcados pela inspetoria geral para a primeira conferência pedagógica. In: BRASIL. Relatório do Ministro dos Negócios do Império, João Alfredo Correa de Oliveira, de 1873. Rio de Janeiro: Tipografia Nacional, 1873, anexo A-B20.

CUNHA, Antonio Estevam da Costa e. Co-educação dos sexos. In: BRASIL. Relatório do Ministro dos Negócios do Império, João Alfredo Correa de Oliveira, de 1873. Rio de Janeiro: Tipografia Nacional, 1873, anexo A-B8.

FARIA FILHO, Luciano Mendes de; MACEDO, Eunice Fontoura de Paula. A feminização do magistério em Minas Gerais (1860-1910): política, legislação e dados estatísticos. CONGRESSO BRASILEIRO DE HISTÓRIA DA EDUCAÇÃO, 3, 2004. Anais ... Curitiba: PUC-PR, 2004.

GONDRA, José Gonçalves; SCHUELER, Alessandra. Educação, poder e sociedade no império brasileiro. São Paulo: Cortez, 2008.

HAHNER, June E. Escolas mistas, escolas normais: a coeducação e a feminização do magistério no século 19. In: Estudos Feministas, Florianópolis, v. 19, n. 2, 2011, p. 467-474.

LOPES, Antônio de Pádua Carvalho. Imagens do masculino e do feminino: coeducação e profissão docente no Piauí (1874-1910). In: FARIA FILHO, Luciano Mendes (org.). Pesquisa em história da educação: perspectivas de análise, objetos e fontes. Belo Horizonte: HG, 1999, p. 95-110.

MIGUEL, Maria Elisabeth Blanck (org.). Coletânea da documentação educacional paranaense no período de 1854 a 1889. Campinas: Autores Associados, 2000.

MIGUEL, Maria Elisabeth Blanck; MARTIN, Sonia Dorotea (org.). Coletânea da documentação educacional paranaense no período de 1854 a 1889. Brasília: Inep/SBHE, 2004.

MUNICÍPIO da Corte. Escolas públicas da corte do Império no ano de 1873. Relatório apresentado pela comissão visitadora das escolas públicas em abril de 1874. In: BRASIL. Relatório do Ministro dos Negócios do Império, João Alfredo Correia de Oliveira de 1874. Rio de Janeiro: Tipografia Nacional, 1874. Anexo B-7

MUNICÍPIO da Corte. Pontos do programa para a primeira conferência pedagógica. Publicado como anexo C-3 do relatório do Ministro dos Negócios do Império, João Alfredo Corrêa de Oliveira, de dezembro de 1872. Rio de Janeiro: Tipografia Nacional, 1872.

MUNICÍPIO da Corte. Inspetoria Geral de Instrução Primária e Secundária. Relatório do Inspetor Geral Antonio Herculano de Souza Bandeira Filho, de 1884. Apresentado ao Ministério dos Negócios do Império e publicado como anexo C-7 do Relatório do Ministro dos Negócios do Império, Francisco Antunes Maciel, de 1884. Rio de Janeiro: Tipografia Nacional, 1884.

PROVÍNCIA de Mato Grosso. Inspetoria Geral dos Estudos. Relatório do inspetor, Dermevil José dos Santos Malhado, de 17 de agosto de 1880. Publicado como Anexo C do relatório do presidente da Província Barão de Maracajú de 1880. Cuiabá: Tipografia de Joaquim J. R. Calháo, 1880. 
PROVÍNCIA de São Paulo. Lei n. 34 de 16 de março de 1846. Organiza a instrução pública primária e cria uma Escola Normal na capital da Província. Coleção das Leis promulgadas pela Assembleia Legislativa desde 1835 até 1888. São Paulo: Tipografia Imparcial de Azevedo Marques, 1868.

PROVÍNCIA do Rio de Janeiro. Regulamento da Instrução Primária e Secundária de 24 de dezembro de 1859. In: Coleção de Leis, Decretos e Regulamentos da Província do Rio de Janeiro de 1859. Rio de Janeiro: Tipografia Nacional, 1868, p. 299-322.

PROVÍNCIA do Rio de Janeiro. Regulamento da Instrução Primária e Secundária de 30 de abril de 1862. In: Coleção de Leis, Decretos e Regulamentos da Província do Rio de Janeiro. Rio de Janeiro: Tipografia Cosmopolita, 1873, p. 43-73.

PROVÍNCIA do Rio de Janeiro. Regulamento da Instrução Pública de 16 de dezembro de 1876. In: Coleção de Leis, Decretos, Atos e Decisões do Governo da Província do Rio de Janeiro de 1876. Rio de Janeiro: Imperial Instituto Artístico, 1877, p. 277-339.

PROVÍNCIA do Rio de Janeiro. Relatório da comissão nomeada pela deliberação de 29 de março de 1882. Apresentado ao presidente da Província Bernardo Avelino Gavião Peixoto. Publicado como Anexo A-1 do relatório do presidente Bernardo Avelino Gavião Peixoto, de 1883. Rio de Janeiro: Tipografia Montenegro, 1883.

PROVÍNCIA do Rio de Janeiro. Diretoria da Instrução Pública. Relatório do diretor Josino do Nascimento Silva de 3 de julho de 1885. Publicado como Anexo S-4 do relatório do presidente José Cesário de Faria Alvim, de 1885. Rio de Janeiro: Tipografia Montenegro, 1885.

PROVÍNCIA do Rio de Janeiro. Diretoria da Instrução Pública. Relatório do diretor Manuel Ribeiro de Almeida de 30 de junho de 1888. Publicado como Anexo S-6 do Relatório do presidente José Bento de Araújo, de 1888. Rio de Janeiro: Tipografia Montenegro, 1888.

SÁ, Carolina Mafra de; ROSA, Walquíria Miranda. História da feminização do magistério no Brasil: uma revisão bibliografia. CONGRESSO BRASILEIRO DE HISTÓRIA DA EDUCAÇÃO, 3, 2004. Anais ... Curitiba: PUC-PR, 2004.

SÁ, Nicanor Palhares; SIQUEIRA, Elizabeth Madureira. Leis e regulamentos da instrução pública do Império em Mato Grosso. Campinas: Autores Associados, 2000.

ANDRÉ PAULO CASTANHA é professor do Colegiado de Pedagogia e do mestrado em Educação da Universidade Estadual do Oeste do Paraná, campus de Francisco Beltrão. Historiador e mestre em Educação pela UFMT, doutor em Educação pela UFSCar e pós-doutor na área de Filosofia e História da Educação pela Unicamp.

Endereço: Rua Antonio Marcelo, 376 - 85605-440 - Francisco Beltrão - PR - Brasil.

E-mail: andrecastanha66@gmail.com.

Recebido em 3 de novembro de 2014.

Aceito em 22 de junho de 2015. 